\title{
Caries and obesity in 6 year-old schoolchildren from the Metropolitan region (MR) of Santiago, Chile
}

\author{
Cárie e obesidade em escolares com seis anos de idade da \\ Região Metropolitana (RM) de Santiago do Chile
}

\begin{abstract}
Purpose: Dental caries and obesity are multifactorial diseases of high prevalence in Chilean child population, and both are preventable from early age. They share association with diet habits and socio-cultural determinants. The objective of this study was to determine the coexistence between caries and obesity in 6 year-old schoolchildren from the Metropolitan Region of Santiago, Chile.

Methods: A sample was composed by 5716 year-old schoolchildren from the fluoridated communes of the Metropolitan Region of Santiago, Chile, in 2004-2005. Caries diagnosis was performed by using the WHO criteria for epidemiological studies. Nutritional diagnosis was carried out according to $\mathrm{BMI} / \mathrm{age}$ and sex in relation to $\mathrm{CDC}-\mathrm{NCHS}$ curves, considering obese children with $a \geq 95$ percentile. Socioeconomic level (SEL) and sex were recorded.

Results: No statistically significant difference was found between caries history and nutritional status (NS) $(P=0.837)$, in both primary and permanent dentition $(P=0.306)$. There was no risk association (OR 0.88; IC 0.60-1.28; 95\%). Overweight children had less caries prevalence and history than normal weight and obese children. No relationship was found at the multivariate analysis between NS, SEL and caries occurrence.

Conclusion: Obesity is not related to dental caries in this sample. Overweight children had less caries prevalence and severity.
\end{abstract}

Key words: Dental caries; obesity; nutritional status

\section{Resumo}

Introdução: A cárie dentária e obesidade são doenças multifatoriais de alta prevalência na população infantil do Chile, e ambos são evitáveis desde a primeira infância. Estas doenças compartilham associações com hábitos alimentares e sócio-culturais determinantes. O objetivo deste estudo foi determinar a coexistência entre cárie e obesidade na população escolar de 6 anos na Região Metropolitana de Santiago, Chile. Metodologia: A amostra foi constituída por 571 escolares de 6 anos residentes nas comunidades com água fluoretada da Região Metropolitana de Santiago, Chile, em 2004-2005. Para diagnóstico de cárie foi aplicado o critério da OMS para estudos epidemiológicos. O diagnóstico nutricional foi realizado segundo o IMC/idade e sexo em relação às curvas CDC-NCHS, considerando-se obesas as crianças com percentil $\geq 95$. As variáveis de nível socioeconômico (SEL) e sexo foram registrados. Resultados: Não houve diferença significativa entre história de cárie e estado nutricional (NS) $(P=0,837)$, tanto na dentição primária quanto na permanente $(P=0,306)$. Não houve associação de risco (OR 0,88; IC 0,60-1,28; 95\%). As crianças com sobrepeso tiveram menor prevalência de cárie e da história do que as com peso normal ou obesas. Não houve relação significativa entre NS, SEL e ocorrência de cárie na análise multivariada. Conclusão: A obesidade não está relacionada com cárie dentária nesta amostra. As crianças com sobrepeso tiveram menor prevalência e severidade de cárie.

Palavras-chave: Cárie; obesidade; estado nutricional; crianças

\author{
Ismael Yévenes $\mathbf{L}$ a \\ Gisela Zillmann G b \\ Andrea Muñoz $M$ a \\ Viviana Mieres Araya ${ }^{b}$ \\ Lorena Coronado $\mathrm{V}$ a \\ José Manríquez $U$ a \\ Fabiola Werlinger C a \\ Paula Maass $\mathbf{W}$ a \\ Renata Quintana B a
}

\begin{abstract}
- Department of Basic Sciences, Dental School, University of Chile, Santiago, Chile

${ }^{b}$ Department of Restorative Dentistry, Dental
\end{abstract} School, University of Chile, Santiago, Chile

\author{
Correspondence: \\ Ismael Yévenes \\ Department of Chemistry, Dental School \\ University of Chile \\ Sergio Livingstone (ex-Olivos) 943, \\ Independencia, Santiago - Chile \\ 838-049 \\ E-mail: iyevenes@odontologia.uchile.cl
}

Received: November 21, 2011

Accepted: April 11, 2012

Conflict of Interests: The authors state that there are no financial and personal conflicts of interest that could have inappropriately influenced their work.

Copyright: (C) 2011 Yévenes et al.; licensee EDIPUCRS. This is an Open Access article distributed under the terms of the Creative Commons AttributionNoncommercial-No Derivative Works 3.0 Unported License. 


\section{Introduction}

Dental caries is a multifactorial, infectious and transmissible disease, which affects a high percentage of the population in all parts of the world. Frequent consumption of a diet rich in carbohydrates is considered one of the predisposing factors for caries occurrence (1). Overweight and obesity are related to an excessive intake of soft drinks, portion size increase and modern lifestyles, characterized by a progressive decrease of physical activity (2).

Possible association between obesity and dental caries may occur due to their common origin in eating patterns. In some populations, these patterns not only produce a caloric imbalance leading to weight gain, but also have implications in oral health. A previous study in the United States reported association between dental caries and deficient diets, which include: skipping breakfast, low intake of fruits and high consumption of carbohydrates in carbonated beverages (3).

Diseases like obesity and caries share a multifactorial etiology related to an excessive intake of certain types of nutrients, eating patterns, lifestyles and socio-cultural determinants, which suggest the coexistence of both diseases in some populations (4). However, exogenous or nutritional obesity is normally related to an increase of calories and fat in energetically dense food, and to sedentary lifestyles $(1,2,5)$, while caries is often related to fermentable carbohydrates by acidogenic bacteria (6-8). Moreover, fat content in food is considered a protective factor against caries injuries development (8).

Some studies with proper methodology in pediatric populations obtained contradictory results when evaluating the association between caries and obesity (9). There is still inconclusive information about the relationship between caries and obesity; this association would depend on the interaction of multiple factors. Therefore, this study evaluated if child obesity is related to dental caries, using a representative sample of 6 year-old schoolchildren from the Metropolitan Region of Santiago, Chile. The specific aim was to identify the population at greater risk and to provide evidences for prevention strategies for both diseases, focusing in oral health as part of child's comprehensive healthcare.

\section{Methods}

Type of study: Descriptive, transversal, epidemiological study, stratified by socioeconomic level, in accordance with the Commune Poverty Ranking elaborated by the 2003 National Socioeconomic Survay (CASEN). A sample of 6 year-old children were selected through the records of the original study "Caries and fluorosis in the Santiago metropolitan region in Chile: The impact of the fluoridation of the water", carried out by the Dental School of the University of Chile for the Chilean Health Ministry between 2004 and 2005. In this study, parents were asked to sign the informed consent.

Pilot study: The pilot sample was composed by 45 children, representative of all the socioeconomic and educational levels considered in this study. The four examiners participating in the study (expert professionals) were calibrated in clinical and administrative aspects. They were instructed about diagnosis criteria, coding and forms. Calibration was performed in a school (Basic School of Recoleta Commune) laying the children on a couch or between two chairs, lighted by a desk lamp, using a 100-W light bulb, and the examiner located behind the head's patient ( 0 hours). For interpersonal calibration each examiner treated 20 children in one opportunity, and the same examiner examined twice a group of 10 patients in different opportunities. Inter-examiner agreement was Kappa $=93 \%$.

Clinical evaluation: The WHO methodology (10) for epidemiological studies was used to record the caries prevalence and the number of caries-free children. Dental caries severity was evaluated with the DMFT index developed by Henry Klein and Caroll Palmer, and the dmft index introduced by Grubbel for primary dentition.

Nutritional status was diagnosed by using the BMI (Body Mass Index) by sex and age, comparing it to the CDC-NCHS reference, using the cut-points suggested by the Health Ministry Technical Norm (11). BMI is the ratio of weight (expressed in $\mathrm{kg}$ ) to height square (expressed in $\mathrm{m}$ ), as follows: $\mathrm{BMI}=$ weight $/$ size $^{2}$. Measuring of weight and size were standardized with the child measurements being recorded without shoes and with light clothes. It was used a 9-V CAMRY ED-301 electronic balance, calibrated at each session. Height was measured in $\mathrm{cm}$, using a metallic measuring tape fixed to the wall.

Data were analyzed by Kruskal-Wallis test and Odds Ratio (OR) with a confidence interval (CI) of 95\%, using dichotomized variables. Multiple variables were analyzed using logistic regression analysis, after dichotomizing sex, socioeconomic level and caries history variables (Table 1).

Table 1. Dichotomized variables for the multivariate model

\begin{tabular}{|c|c|}
\hline Variable & Code \\
\hline Sex & $\begin{array}{l}0=\text { Male } \\
1=\text { Female }\end{array}$ \\
\hline Nutritional status & $\begin{aligned} 0= & \text { Normal } \\
1= & \text { Not normal } \\
& \quad \text { (underweight, overweight, obese) }\end{aligned}$ \\
\hline Socioeconomic level & $\begin{array}{l}0=\text { High sel } \\
1=\text { Low and middle sel }\end{array}$ \\
\hline Caries history & $\begin{array}{l}0=\text { Without caries history }(\mathrm{DMF} / \mathrm{DMF}=0) \\
1=\text { With caries history }(\mathrm{DMF} / \mathrm{DMF}=0)\end{array}$ \\
\hline
\end{tabular}

\section{Results}

From a sample of 571 children, $254(44.48 \%)$ were males and $317(55.52 \%)$ were females $(P=0.021)$.

Descriptive statistics are shown in Tables 2 and 3. According to the socioeconomic level, sample distribution was of 110 children $(19.26 \%)$ belonging to the high 
socioeconomic level, 166 children $(29.07 \%)$ belonging to the middle SEL, and 295 children (51.66\%) belonging to the low SEL.

According to the BMI, the distribution of the 571 children was as following: 15 children were underweight (2.67\%), 290 children were normal-weight (50.8\%), 136 children were overweight (23.8\%), and 130 children were obese $(22.8 \%)$. The percentage of children with malnutrition by excess in this sample was of a $46.5 \%$.

From the total sample, a $70.75 \%$ presented caries history (404 children), while a $29.25 \%$ were caries-free. Caries history measured in deciduous dentition obtained an average of 2.92 (dmft) and 0.28 in permanent dentition (DMFT), which are broken down as follows: Decayed (d) 1.68-0.19, filled (f) 1.1-0.09, and diagnosed extraction teeth (de) 0.12-0, respectively. The highest component in caries history in both dentitions was a decayed tooth.

The association between caries and sex did not show significant difference neither in temporary dentition $(P=0.943)$ nor in permanent dentition $(P=0.199)$, (MannWhitney). When estimating the association measure, it was obtained an $\mathrm{OR}=1.025$ (CI 95\%: 0.7-1.5).

Conversely, it was found a statistically significant difference in caries prevalence in relation to the different socioeconomic levels between caries and SEL $(P=0.034)$. A $66 \%$ of children belonging to the high socioeconomic level presented caries history, while this occurred in a $65 \%$ in children of the middle socioeconomic level, and in a $75 \%$ in children of the low socioeconomic level. There was no association between caries and socioeconomic level, $\mathrm{OR}=0.775$ (CI 95\%: 0.48-1.25).
No significant difference was found among normalweight, overweight, and obese children in relation to caries history in deciduous $(P=0.837)$ and permanent dentition $(P=0.306)$. Both prevalence results and caries history in overweight children were lower in comparison with normalweight and obese children, which was not significant (Table 2)

In the bivariate analysis of caries history and nutritional status as dichotomous variables, there was no risk association $(\mathrm{OR}=0.88 \mathrm{CI} 95 \%$ of $0.60-1.28)$ when using caries history as a dependent variable. When using the nutritional status as a dependent variable there was no risk association either $(\mathrm{OR}=0.88 \mathrm{CI} 95 \%$ of $0.60-1.28)$ (Table 3$)$.

There were no significant difference $(P=0.606)$ between sex and nutritional status. No risk association was found, $\mathrm{OR}=1.08$ (CI $95 \%$ of $0.70-1.68$ ), but there was a higher proportion of overweight girls $(27.13 \%)$ than overweight boys $(19.69 \%)$.

A statistically significant difference was found for the nutritional status in relation to socioeconomic level $(P=0.023)$. No risk association was shown in the bivariate analysis using the nutritional status as a dependent variable, $\mathrm{OR}=1.08$ (CI 95\%: 0.70-1.68). Lower prevalence of overweight and obese children was found in the low socioeconomic level (42\%) (Table 3).

Multivariate models: When building a multivariate model of logistic regression to predict caries occurrence by nutritional status, socioeconomic level and sex as independent variables, none of their combinations were associated to caries occurrence $(\mathrm{dmf} / \mathrm{DMF}>0)$, which was the dependent variable. No significant differences were found for any of their combinations in caries occurrence (Table 4).

Table 2. Decay damage by sex, socioeconomic level and nutritional status

\begin{tabular}{lccccccccc}
\hline & \multicolumn{2}{c}{ Sex } & \multicolumn{3}{c}{ SEL } & \multicolumn{3}{c}{ Nutritional Status } \\
& Male & Female & High & Middle & Low & Underweight & Normal-weight & Overweight & Obesity \\
\hline dmft & 2.93 & 2.91 & 2.8 & 2.59 & 3.17 & 2.8 & 3.02 & 2.73 & 2.9 \\
DMFT & 0.22 & 0.32 & 0.16 & 0.32 & 0.3 & 0.13 & 0.24 & 0.31 & 0.35 \\
\hline
\end{tabular}

SEL: Socioecomic level.

Table 3. Prevalence of caries by sex, socioeconomic level and nutritional status

\begin{tabular}{|c|c|c|c|c|c|c|c|c|c|c|c|c|c|c|c|c|c|c|}
\hline & \multicolumn{4}{|c|}{ Sex } & \multicolumn{6}{|c|}{ SEL } & \multicolumn{8}{|c|}{ Nutritional Status } \\
\hline & \multicolumn{2}{|c|}{ Male } & \multicolumn{2}{|c|}{ Female } & \multicolumn{2}{|c|}{ High } & \multicolumn{2}{|c|}{ Middle } & \multicolumn{2}{|c|}{ Low } & \multicolumn{2}{|c|}{ Underweight } & \multicolumn{2}{|c|}{ Normal-weight } & \multicolumn{2}{|c|}{ Overweight } & \multicolumn{2}{|c|}{ Obesity } \\
\hline & $\mathrm{n}$ & $\%$ & $\mathrm{n}$ & $\%$ & $\mathrm{n}$ & $\%$ & $\mathrm{n}$ & $\%$ & $\mathrm{n}$ & $\%$ & $\mathrm{n}$ & $\%$ & $\mathrm{n}$ & $\%$ & $\mathrm{n}$ & $\%$ & $\mathrm{n}$ & $\%$ \\
\hline Caries-free & 75 & 29.53 & 92 & 29.02 & 37 & 33.64 & 58 & 34.94 & 72 & 24.41 & 6 & 40 & 81 & 27.93 & 41 & 30.07 & 39 & 30 \\
\hline $\begin{array}{l}\text { With caries } \\
\text { history }\end{array}$ & 179 & 70.47 & 225 & 70.98 & 73 & 66.36 & 108 & 65.06 & 223 & 75.59 & 9 & 60 & 209 & 72.02 & 94 & 69.63 & 91 & 70 \\
\hline
\end{tabular}

SEL: Socioecomic level.

Table 4. Multivariate model. Caries presence in relation to socioeconomic level, sex and nutritional status variables

\begin{tabular}{lcccc}
\hline \multirow{2}{*}{ Caries } & \multicolumn{4}{c}{$P=0.63$} \\
\cline { 2 - 5 } & OR & SDeudo $R^{2}=0.0025$ \\
\hline Socioeconomic level & 0.78 & 0.18 & 0.27 & $0.49-1.21$ \\
Sex & 1.02 & 0.19 & 0.91 & $0.71-1.47$ \\
Nutritional Status & 0.89 & 0.16 & 0.49 & $0.61-1.26$ \\
\hline
\end{tabular}

P: P of multivariate model; OR: Odds Ratio; SD: Standard deviation; Pseudo R2: Pseudo-correlation coefficient; $P>|z|: P$ of the variable in the multivariate model; $\mathrm{Cl}$ : confidence interval. 


\section{Discussion}

In the present study, we evaluated the association between obesity and caries in a representative sample of schoolchildren aged 6 year-old from the Metropolitan Region of Santiago, Chile. No association was found between nutritional status and dental caries. There was also no relation between nutritional status and socioeconomic level as covariates to predict caries occurrence.

These results are comparable to those by Soto et al. at the national and Metropolitan Region level in 2007 (13). In the present study, the caries prevalence was $70.75 \%$, whereas in Soto et al. the figures were $70.36 \%$ at the national Chilean level and $68.36 \%$ in the Metropolitan Region of Santiago. Regarding caries history, we found 2.92 in deciduous dentition and 0.28 in permanent dentition, while Soto et al. reported 3.71 and 0.16 caries in deciduous dentition and permanent dentition, respectively, at the national level. It was not found significant difference in caries prevalence in relation to sex, differently from Soto et al., who found that women $(\mathrm{dmft}=3.44)$ presented less damage than men $(\mathrm{dmft}=3.95)(13)$.

There was a significant difference in caries prevalence and history in relation to socioeconomic level in the deciduous dentition. We found that 1.14 children of the low SEL had caries history in deciduous dentition for each children of the high SEL with caries history. These results are similar to those by Soto et al., who reported the highest accumulated damage in 6 year-old children at the low socioeconomic level $-4.41 \mathrm{dmft}$, a value that is higher than the national average of 3.71 (13).

Regarding the nutritional status, caries prevalence in overweight and obese children was of $23.8 \%$ and $22.7 \%$, respectively, values that are higher than those found in 2006 at the national level report, where a $19.4 \%$ of the schoolchildren attending the first grade of primary education were obese (17).

Variation in nutritional status was not related to sex, but socioeconomic level was a significant factor. The children from the middle socioeconomic level had higher prevalence of overweight and obesity status than children from the high and low SELs, while the children of the lower SEL had the lowest prevalence of malnutrition. These results do not coincide with the international evidence, where obesity is related to high poverty levels. Nevertheless, Adjemian et al. (18) also found no significant difference between the BMI by SEL, although children of the lowest SEL presented the lowest values of BMI, arm fold and circumference, and food consumption. Adjemian et al. highlighted the sedentary lifestyle as a possible cause of these results, since the children of the lower socioeconomic level were physically more active than those of the other groups, because they used more often the communitary places and walk to and from school (18).

Normal-weight, overweight and obese children had similar caries prevalence and history for both deciduous and permanent dentitions. Caries prevalence was $72.1 \%$ in normal-weight children, $69.9 \%$ in overweight children, and $70 \%$ in obese children. With respect to caries history, the mean values of $\mathrm{dmft}$ were 3.02 in normal-weight children, 2.72 in overweight children, and 2.9 in obese children. Overweight children had less caries prevalence and history (dmft) than normal weight and obese children. These results are in agreement with recent studies carried out in other countries, where no relation was found between caries and obesity (19-22). Some suggest that even being overweight might be a protective factor against caries occurrence $(23,24)$. Also, Kopycka-Kedzierawski et al. (23) reported that in 17,748 children participating in the United States NHANES III survey (1988-1994) and NHANES (1999-2002) there was not enough evidence to suggest that overweight children had an increased risk of having caries. Instead of a positive association between obesity and an increased risk of caries, Kopycka-Kedzierawski et al. (23) found that overweight was associated to a lower number of dental caries, i.e., a lower caries risk, in the group of children aged 6 to 11 years, according to the data analysis of NHANES III (1988-1994). These findings were corroborated by Hong L. et al. (21), who carried out a study in 1,507 children from 2 to 6 years old in the United States NHANES 1999-2002, where no significant association was recorded between obesity and caries occurrence. Conversely, Macek and Mitola (22) found that overweight children had lower DMFT index in a sample of children from 2 to 17 years old, in NHANES (1999-2002). In addition, there was no association between BMI by age/ sex and caries prevalence, which are also in agreement with the present study.

The systematic review by Kantovitz (9) showed contradictory results for the relationship between caries and obesity, since only one study (24) described significant differences in prevalence and caries between normal-weight and obese children, while two studies $(19,20)$ did not find any relation.

Our findings are in accordance with those by Tapia et al., who reported that obesity was not a caries risk factor in 50 obese children and 41 normal-weight children from the schools of the Recoleta commune, Santiago, Chile. However, there are no national studies in large representative samples that evaluated this relationship (26).

Our multivariate model did not show any association among nutritional status, socioeconomic level, and sex as covariates for caries occurrence, which is not in agreement with the findings by Marshall (27) in a longitudinal study of 427 American children aged 4.5 to 6.9 years, where low socioeconomic level increased both caries risk and obesity. In our study, obesity and overweight were more prevalent in the middle socioeconomic level (53.6\%).

It should be considered that only the data of children belonging to the 26 communes receiving fluorine in the Metropolitan Region was analyzed. It is widely known the impact of fluorine on the relationship between diet and caries, with focus on epidemiological studies have found that the current association between sugar consumption and caries is weaker than in times before the introduction of 
fluorine $(28,29)$. It is possible that the relationship between obesity and caries may have been modified by the effect of fluorine in diet and caries relationship, oral health preventive programs, and oral hygiene habits, despite of the frequent consumption of sucrose. This could explain the negative results of the present study on the relationship between caries and obesity. However, diet counseling should be incorporated by oral healthcare programs, since it may prevent malnutrition by excess of food consumption and its consequences, as well as dental caries, according to the individual risk level.

\section{Conclusions}

This study found no association between caries and nutritional status in both deciduous and permanent dentitions, which suggest no relation between obesity and caries in this sample of children. In the multivariate model analysis, nutritional status, socioeconomic level and sex as covariates did not predict caries occurrence. No statistically significant difference was found in nutritional status in relation to the socioeconomic level.

Despite this study does not reveal any association between obesity and caries variables, the high prevalence of malnutrition indicates that its prevention through diet counseling should be included in dental work and in schools as well, within a multidisciplinary context, focused on groups of high risk for caries and obesity.
References
1. Uauy R, Albala C, Kain J. Obesity trends in Latin America: Transiting from under- to overweight. J Nutrition 2001;131:839S-899S.

2. Dehghan M, Akhtar-Danesh N, Merchant AT. Childhood obesity, prevalence and prevention. Nutr J 2005;4:24

3. Dye BA, Shenkin JD, Ogden CL, Marshall TA, Levy SM, Kanellis MJ. The relationship between healthful eating practices and dental caries in children aged 2-5 years in the United States, 1988-1994. J Am Dent Assoc 2004;135:55-66.

4. Palmer CA. Dental Caries and obesity in children: Different problems, related causes. Quintessence International 2005;36:457-61.

5. World Health Organization. Diet, nutrition and the prevention of chronic diseases. Geneve 2003. Technical Report Series 919.

6. Featherstone J. The science and practice of caries prevention. J Am Dent Assoc 2000;131:887-99.

7. Featherstone J. The continuum of dental caries - Evidence for dynamic disease process. J Dent Res 2004;83(Spec Iss C):C39-C42.

8. Bowen WH. Food components and caries. Adv Dent Res 1994;8:215-20.

9. Kantovitz KR, Pascon FM, Rontani RM, Gaviao MB. Obesity and dental caries - a systematic review. Oral Health Prev Dent 2006;4:137-44.

10. World Health Organization (1997). Oral Health Surveys: Basic Methods. $4^{\text {th }}$ Edition. Geneva: World Health Organization.

11. Chilean Health Ministry. 2007. Technical Norm for the nutritional evaluation of children aged 6 to 18 years old.

12. Yévenes I, Zillmann G, Muñoz A, Aranda W, Echeverria S, Hassi J et al. Caries and fluorosis in the Santiago metropolitan region in Chile: The impact of the fluoridation of the water. Rev Odonto Cienc 2011;26:109-15. .

13. Soto L, Tapia R, et al. National diagnosis of oral health in 6 years old children. Chile 2007. Chilean Health Ministry.

14. World Health Organization (1972). Etiology and prevention of dental caries. Geneva. Technical Documents Series 949.

15. Tinanoff N, Kanellis MJ, Vargas CM. Current understanding of the epidemiology, mechanisms and prevention of dental caries in preschool children. Pediatr Dent 2002;24:543-51.

16. Feigal RJ, Donly KJ. The use of pit and fissure sealants. Paediatr Dent 2006;28:143-50.

17. Nutritional situation of Chilean schoolchildren of first grade. http://venus.junaeb.cl/ estadosnutricionales 2007/index.php

18. AdjemianHYPERLINK" "http://translate.googleusercontent.com/translate c? hl=es\&langpa ir $=$ en\%7Ces\&rurl =translate.google.cl\&u=http://www.ncbi.nlm.nih.gov/pubmed\%3Fterm \%3D\%2522Adjemian\%2520D\%2522\%255BAuthor\%255D\&usg=ALkJrhhFOSVGTTZLCB n6Lp0sxa4lcOBvEw" D, Bustos P, Amigo H. Socioeconomic level and nutritional status: a study in schoolchildren. Arch Latinoam Nutr 2007;57:125-9.

19. Tuomi T. Pilot study on obesity in caries prediction. Community Dent Oral Epidemiol 1989;17:289-91

20. Chen W, Chen P, Chen SC, Shih WT, Hu HC. Lack of association between obesity and dental caries in three year-old children. Chen Zhongua Min Guo Xiao Er Ke Yi Xue Hui Za Zhi 1998;39:109-11. 
21. Hong L, Ahmed A, McCunniff M, Overman P, Mathew M. Obesity and Dental Caries in Children Aged 2-6 Years in the United States: National Health and Nutrition Examination Survey 1999-2002. J Public Health Dent 2008;68:227-33.

22. Macek MD, Mitola DJ. Exploring the association between overweight and dental caries among US children. Pediatric Dent 2006;28:375-80.

23. Kopycka-Kedzierawski DT, Auinger P, Billings RJ, Weitzman M. Caries status and overweight in 2- to 18-year-old US children: findings from national surveys. Community Dent Oral Epidemiol 2008;36:157-67.

24. Willershausen B, Haas G, Krummenauer F, Hohenfellner K. Relationship between high weight and caries frequency in German elementary school children._Eur J Med Res 2004;9:400-4

25. Drewnowski A, Specter SE. Poverty and obesity and energy costs. Am J Clin Nutr 2004;79:1 -6.

26. Tapia M, Zillmann G, Sepulveda R, Jara A. Caries prevalence in normal-weight and obese children of first grade of primary education in municipal establishments and charter schools, Commune of Recoleta, Santiago. Rev Soc Chilena de Odontopediatría 2004;18:34.

27. Marshall TA, Eichenberger-Gilmore JM, Broffitt BA, Warren JJ, Levy SM. Dental caries and childhood obesity: roles of diet and socioeconomic status. Community Dent Oral Epidemiol 2007;35:449-58.

28. Touger-Van Loveren. Sugars and dental caries. Am J Clin Nutr 2003;78(suppl):881S-92S.

29. Zero DT. Sugars - the arch criminal? Caries Res 2004:38:277-85. 